\title{
The adoption of multidimensional exploration methodology to the design-driven innovation and production practices in AEC industry
}

\author{
Zeynep Birgonul ${ }^{* 1}$ iD, Oriol Carrasco ${ }^{2}$ iD \\ ${ }^{1}$ Universitat Internacional de Catalunya, Department of Architecture, Barcelona, Spain \\ ${ }^{2}$ Institute for Advanced Architecture of Catalunya, Department of Architecture, Barcelona, Spain
}

\begin{abstract}
The new horizon for research \& development in AEC is directed through an interdisciplinary design-thinking approach. The design paradigms are not only as they were about form and function but now also about efficiency, sustainability, productivity, desirability, feasibility, and viability in current day. As a result of this approach, the term design innovation approves oneself. Correspondingly, emerging technologies such as robotic fabrication \& construction tools, self-fabrication \& assembly, information and communication technologies, computer science and related software technologies, enable the designers and engineers to push the edges of their creativity, productivity and sensitivity upon global issues. The emergence of those new technologies is defined as digitalism, and both academy and industry have almost totally adapted to this digital-design thinking approach. Consequently, the smooth communication between machines, makers and designers dominates the progression in architecture, science, technology and engineering. However, because of this shift, a research gap has emerged between new academic research and classical industrial production as theory and practice do not overlap anymore. For the adoption of this emergent holistic design-thinking approaches; a new learning methodology has been introduced by the authors under the title of 'Multidimensional Exploration Methodology.
\end{abstract}

\section{Keywords}

Design driven innovation; Digital design-thinking; Fabrication and construction tools; Interdisciplinary approach; Prototyping and production practices

Received: 15 June 2021; Accepted: 28 June 2021

ISSN: 2630-5771 (online) @ 2021 Golden Light Publishing All rights reserved.

\section{Introduction}

The Multidimensional Exploration Methodology (MDEM) is a holistic learning approach based on spiral progress loops of design-thinking and experimentation. The main objective of the methodology is to augment the creativity, productivity and learning efficiency thanks to cognitive learning styles and self-challenges that trigger design-driven innovation. This method helps the learner to align with the recent developments in the industry and adapt to the contemporary world as active thinkers and future's change-makers.

The method has three principal variables, such as the student; as an object, the time; as an indicator, and the knowledge flows rate; as the acquisition. MDEM is a combination of various classical and modern learning approaches that augments creativity and design skills, and creating a more responsible manner as well as constantly 
challenging the learner with developing new skills, following technological updates and considering global issues.

In this paper, an adaptation of the Multidimensional Exploration Methodology in education to professional practices in the Architecture - Engineering - Construction (AEC) industry is explained by a conceptual compass diagram. The alternation from digital designthinking education through design-driven innovation and related production practices is also discussed. The aim of this work is to fill the gap between academy and industry by the usage of this methodology, generating design driven innovations that could potentially expedite the progression on the way of sustainable development, innovative results, generation of new knowledge, and environmental conscious design.

\section{Multidimensional exploration methodology}

"Academic knowledge always needs to take earlier knowledge into consideration, and to build upon a similar epistemology... From an academic perspective, this plurality in discourses within designedly ways of thinking is not a sign of weakness but rather a sign of maturity" [1]. The Multidimensional Exploration Methodology applied in academy, empowers the learner with self-challenges on the way of creation of new information and it is completely solution oriented. Throughout the learning loop, the learner seeks an applicable solution for an existing problem with a designedly-way. This approach is completely interdisciplinary, so that the learner must get out of the comfort-zone of a single discipline and investigate and interpret the answers in various other fields for a specific question.

The method is based on various learning methods such as Cognitive Learning Theory [2-3], Kolb's' Experiential Learning Methodology [4-5] and Design Science Research Methodology [6-7]. Our learning methodology is developed based on aforementioned learning techniques and finally adapted to the Challenge-Based Learning theory. 'Challenge-Based Learning (CBL) is a collaborative learning experience in which teachers and students work together to learn about compelling issues, propose solutions to real problems, and take an action. The approach asks students to reflect on their learning and the impact of their actions and publish their solutions to a worldwide audience' [8-9].

The main objective of the new hybrid learning method is to rebuild the cognitive activities of the learner aligned with the new generation architectural design requirements. This method has four main phases within a spiral loop:

- Identification of Objectives

- Performing Risk Analysis

- Developing and Testing

- Review and Evaluation.

This method empowers and inspires the student by their own learning style [10-12] depending on their background, personal life experience, previous knowledge and cognition. "Learning strategies, on the other hand, involve conscious choices about how a learner aims to handle how they will behave in a certain learning situation" [1314]. Relatively, MDEM encourages the learner to concentrate deeply on introspection on the initial stage of learning and design. So that the students intentionally start the design thinking by the previous knowledge and within the scope of their pre-constructed cognition and personal abilities [15]. As, "students are mostly expected to create without a given method as they are to develop their own; the general fallback is that a high ratio of students lacks confidence upon feeling unable or not gifted" [16]; within this methodology, student feels comfortable of choosing the unconditioned way of doing things. As a matter of using cognitive methods, the learner feels more comfortable, motivated and inspired during the very beginning of the project. Especially, concerning digital-design thinking approaches effects of cognitive learning styles of design students are significant [17].

The main contribution of this methodology is to lead the learner to generate knowledge rather than the teacher teaching it in a classical way. Students develop a project during the course, but most important outcome is never the end-result, on the contrary, it is the learning process gains thanks to 
the challenge-based learning. This is the reason why, this method is developed as a spiral graph, so that the learner repeats the process until the required results are achieved and the learner is satisfied.

In Fig. 1, the spiral graph that describes the methodology can be seen. The spiral model is crucial on this method because of the inclusion of risk analyzed learning loops, creating a selfevaluation and exploration process until cognitive activities are transformed into new knowledge. Moreover, thanks to the spiral different phases, the knowledge is not learned from a unique source, yet, thanks to the experiential learning techniques, the learner generates it as is progresses down the design path.

"Design thinking has gained notoriety across various disciplines because its tools and methods are often associated with innovation" [18]. Even though the Multidimensional Exploration Methodology is proposed and applied only to academic learning and research practices so far, yet; it has a great potential to be adapted to professional, industrial and planning practices, such as in industrialization, production and construction.

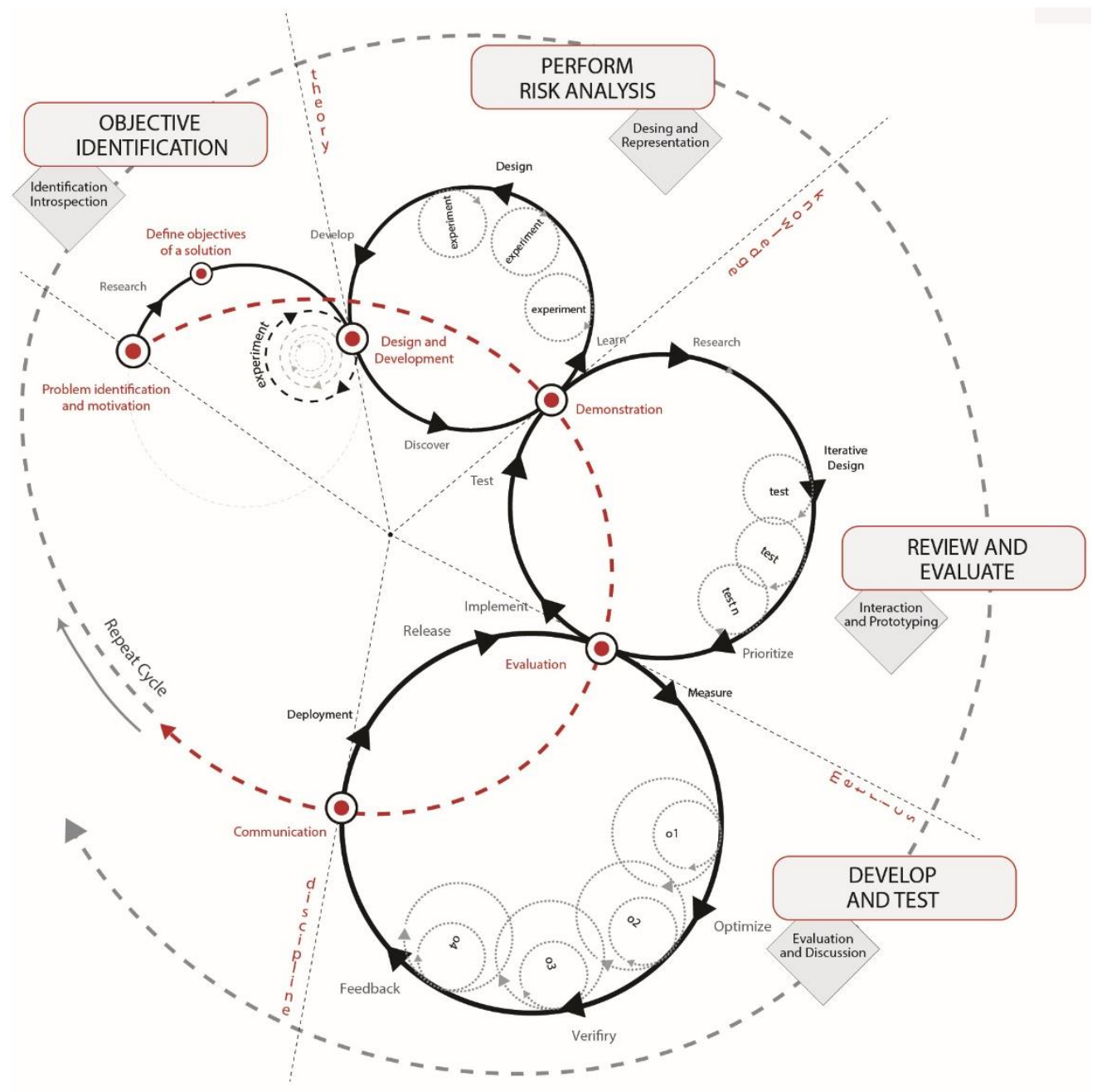

Fig. 1. Multidimensional exploration methodology spiral graph expanded 


\section{Multidimensional exploration method: From academy to industry}

The alignment with the aforementioned new architectural design understanding takes the reference from cognitive background of the young professionals. Architecture, engineering and construction students learn the new contexts and up-to-date methods during the last part of their university education. As a result of this translation of knowledge from university to industry, the regeneration of the cognition upon the requirements of built environment depends on the learnt facts. During the learning period in academy, the student develops skills and generates knowledge by the exploration method, which becomes an intrinsic part of their knowhow and experience.

In Fig. 2, the shift of applied phases from academic research to industrial practice is described. The transition of the generated knowledge from academy (research) to practice (development), could be applied according to the list shown in figure.

Since usually in the academic research the outcomes of the project are mostly theoretical, generally no real application is required. Theory to application needs to be covered in the holistic 'research and development' with prototyping (production) practice. In the industry, the research and development tend to be inseparable, as the development can be based on real testing. By the Multidimensional Exploration Method, prototyping is included as one of learning phases, as it adds a substantial contribution to the generation of knowledge through learning by doing principles, as well as it is used as a tool for upgrading the value of the research projects.
'The Design-thinking educational outcomes ladder diagram' [19-20] explains the journey of the learner by five steps, such as 1. Factual (Understand: interpretating, explaining and identifying), 2. Skills (Apply: implementing, executing, translating), 3. Conceptual (Analyze: deconstructing, differentiating, organizing), 4. Synthesize: (coordinating, criticizing, testing) and lastly, 5. Meta-cognitive: (Evaluate: appraising, valuing, selecting). This model is a reference for the MDEM by summarizing the pathway from the cognitive learning outcomes, and transferring them into skill-based learning outcomes and finally, developing personal affective learning outcomes. Transferring this learning and workflow method to the professional practice is done via the same principles. The spiral model adds more sub-steps and check points to the development scheme. Upon this model, MDEM proposes a more practice-based model, where the learners not only research or learn about a current problem, but also; they eventually produce the design-theory and develops an actual solution for the initial hypothesis or the problem. As a result, the learner becomes the 'knowledge generator' by this approach. The generated information and knowledge would be transferred, by following the spiral loops of the method.

In academic research, the student uses his current skills, previous knowledge and cognition to develop new skills and generate aligned knowledge. In industry, the young professional uses the regenerated cognition and knowledge to develop prudent and innovative products and systems aligned with a much more specific goal that has place in the market.

\section{ACADEMIC RESEARCH}

Identification of the Problem

Introspection (Cognition \& Thinking)

Design: Representation + Simulation

Prototyping (Application)

Testing and Interaction (Evaluation)

Discussion

Knowledge Generation

Loop: Repeat the process until the required goal is fulfilled.

\section{INDUSRTIAL APPLICATION}

Idea

Prudence

Design-Thinking

Knowledge Generation

Prototyping (Application)

Testing, Interaction, Invention

Outcomes (Discussion \& Evaluation)

Added Value

Fig. 2. The shift of applied phases from academic research to industrial development 


\section{Design-driven innovation through MDEM}

Design and innovation processes have been competing throughout the history [21]. Even today, it stands as an important topic in design industry. However, the term design-innovation corresponds to a new paradigm, by proposing a hybrid of design and innovation. This holistic design approach contains design with added values, authentic ideas, actual technologies, sustainable development that develop innovative outcomes. "The focus is on how the design process can be organized and managed towards product and service innovations on corporate and community (users) levels" [22].

The term Digital-Design Thinking includes significant use of new digital paradigms in design and representation practices [23]. Consequently, the design-driven innovation covers up both the design innovation aligned with current digitalized trends, where the term digitalism [24] also applies. After the arise of Industry 4.0, innovative projects are produced via digital-design thinking and design-innovation altogether. Regarding the design and innovation processes, the aforementioned holistic design approach is a key to combine the generated knowledge by research and development in academic world. On the other hand, the current technologies used in the industry can benefit immensely from it. Integrating design thinking models in which strategy building, innovation, and design management become one unified process, has various advantages [25].

Design-driven innovation is an approach that describes how to design an innovation that provides the customer with a new meaning - an added value. The approach is described by [26] as an approach to innovation based on the observation that people do not just purchase products, or services, they buy meaning - where users' needs are not only satisfied by form and function, but also through experience. The experience also could be described as the meaning of the product.

In Fig. 3, the diagram shows the overlapping of the Multidimensional Exploration Methodology spiral method and the Innovative Industrial practice steps. This diagram can be read as a visual reference of the transition from the academic research and development to the Design-Driven Innovation in professional AEC field.

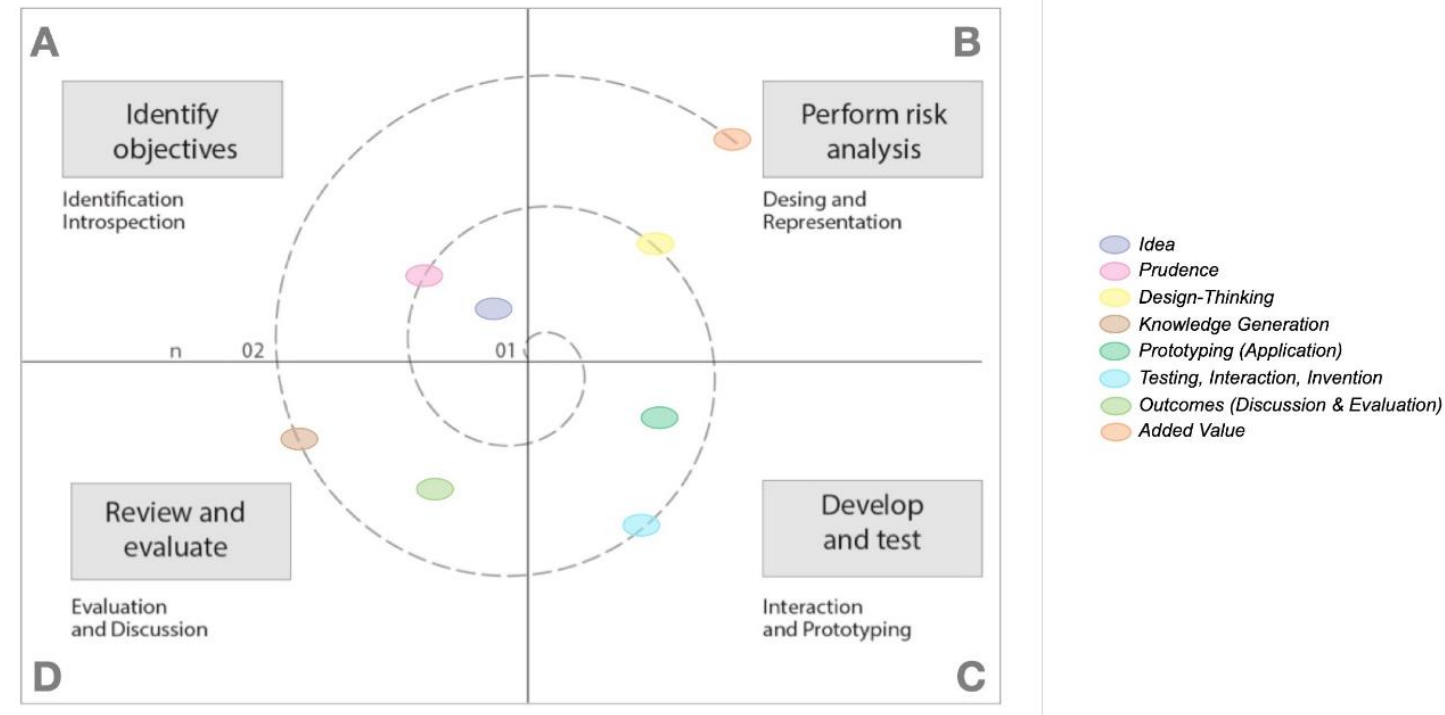

Fig. 3. Multidimensional exploration methodology spiral graph with design driven innovation approach steps 


\section{The design-driven innovation compass}

The theory is that the needs of people are not only satisfied by functions (or technology), but also in the form of experience (meaning). The meaning of a product to the user includes aspects like memories, who gave it, the amount of care and repair involved, enjoyability, and how close the user links the product to the definition of himself. A meaning can therefore make a product embody goals, make skills manifest and shape the identity of its users. But a new meaning can also be designed, for example when adding a social aspect to a previously plain functional product.

The applicability of design-driven innovation:

- Technology push can be created by following an analytical approach.

- Market pull (or user-centered design) can be created by stimulating open innovation.
- Design-driven innovation is an approach that makes use of closed innovation networks and new methods.

- So, learning innovative techniques and learning by a sustainable approach such as Multidimensional Exploration Methodology, applying the gained knowledge by digital design thinking, will enable the practitioner to engage with the emergent technologies and new production practices.

As a result, the design-driven innovation is applied in practice by; Investigation to Innovation and Discovery to Development.

Fig. 4 shows the four poles of the DesignDriven Innovation Compass as;

- Discovery

- Development

- Innovation

- Investigation.

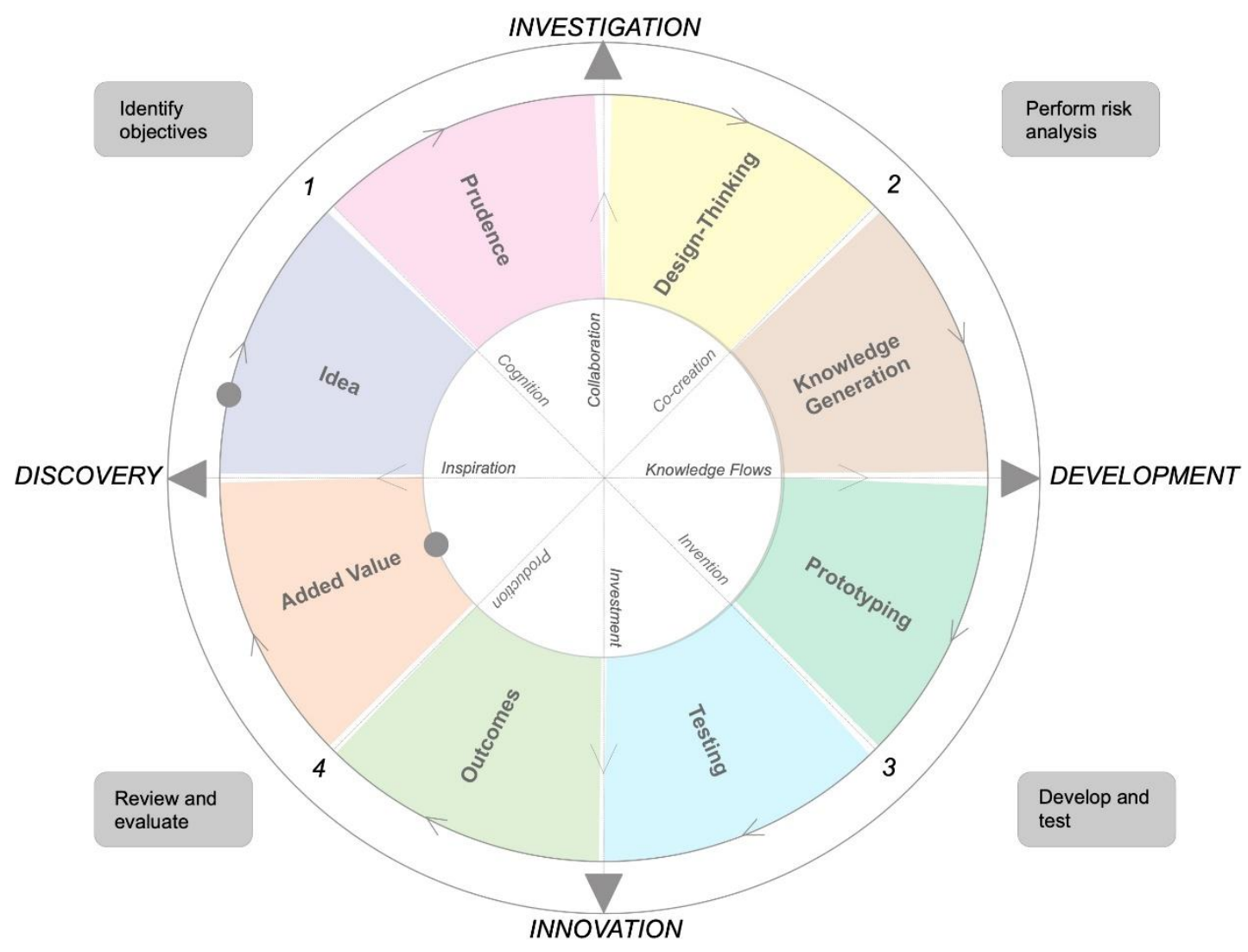

Fig. 3. The design-driven innovation compass 
The approach flows between those conceptual poles, without any significant variety of importance of the terms. Every stage of the research is equallybalanced since the process is not linear. In between of the four main axis, the young practitioner's work should flow through the phases that are adapted from the learning methodology. Starting from the inspiration and the initial idea ( $1^{\text {st }}$ cycle - Discovery to Investigation), the facts should be discussed and evaluated by prudence. Later on, the design thinking and the applicability should be processed. On this phase $\left(2^{\text {nd }}\right.$ cycle - Investigation to Development), digital-design thinking approach should be concerned. Moreover, while the practitioner is designing the project, the learning method is actively used and the person generates new knowledge upon previous research and development examples from academic environment. On the following phase $\left(3^{\text {rd }}\right.$ phase Development to Innovation), the main contribution is done by testing, prototyping and application of new technologies. The tests should continue until the required results are achieved. On the last phase ( $4^{\text {th }}$ phase - Innovation to another Discovery), the spiral loop continues with reviewing and evaluating the outcomes, and documentation of added values. On the last phase, the economic and technologic outcomes are visible, regarding to the feasibility and the originality of the project.

Loops might happen faster or slower, depends on the practitioners' self-pace and evaluation loops within loops do exist in this method. While the four main poles define the principal contributions of design-driven innovation processes, the sub-steps determine the applications and detailing. The substeps also follow each other in a spiral fashion, until the required results are obtained with the following order: inspiration with the initial steps, generates the idea with the scope of cognition in the $1^{\text {st }}$ phase. Afterwards on the $2^{\text {nd }}$ phase, during the investigation, by knowledge flows, collaboration between disciplines and co-creation occurs. During the $3^{\text {rd }}$ phase, as a result of the previous phases, the development of the project by prototypes and testing happens, and might result as concrete invention that was envisioned on phase 1 and 2. On $4^{\text {th }}$ phase, if the invention is successful and worthwhile pursuing, other interest can be further achieved and the project could be developed further as bigger scaled productions.

\section{Current design and production practices in AEC industry}

Regarding the importance of actual software and workflows, productive and efficient visualization and documentation technologies have emerged in relation with the digitalism in AEC industry. As a matter of fact, digital-design thinking and the design-driven innovation are enhanced because they have found proper applications and projects to thrive.

Thanks to the Fourth Industrial Revolution [27], the technologies for data collection have become more eligible and accessible on the last decade. Multitude of sensors are now cheap and available for personal use. Moreover, the user's daily life has adapted to the usage of intelligent embedded systems, smart phone applications, and cameras now surveil the built environment. Since the usage of smartphones has dictated nearly every action of quotidian life, and the personal dataflow is stored in big data, the information of these actions can be accessible and exists for further usage. As a consequence, and even not obvious, people live in a big data cloud. As the term Interactive Architecture indicates, it "includes contributions from the worlds of architecture, industrial design, computer programming, engineering, and physical computing" [28]. By the collaboration of several disciplines with a contemporary understanding, adapting the architecture to the conscience modern worlds' necessities and user's expectations is now the underlaying design thinking process behind the project. "The concept of embedded intelligence in buildings is not new; rather what makes it currently possible are cheap digital sensors, access to computer power to handle big streams of data, and the development of software specifically developed for on-going operations and maintenance of buildings" [29]. Since the technologies of sensing and data collection became eligible and accessible, the design research that corresponds to digital data 
collection also has augmented. Additionally, by the deepening of accuracy in data, the research quality also shows significant increase. On the other hand, the design of the built environment is almost totally adapted to the Digital-Design Thinking [30] and related production methodologies. Recently the digital tools for design, modeling and visualization have been extremely advanced and easy to use, empowering the designers for data-led, environmentally responsible decision-making. The built environment also has become smarter by the help of Internet of Things (IoT) and data gathering devices. As a result, there is a continuous development in smart home technology that translates subsequently into smart cities development. Correspondingly, the built environment is being regenerated by the users and society, rather than by only designers. The new technologies for construction and design, take reference from the real-time information and are able to create reactive environments with live interactions.

For instance, by the prevalence of the usage of Building Information Modeling (BIM), the understanding of the modeling tools swiped from just being a visualization medium to an information smart file that can be built upon reality and accuracy. Architects and engineers use BIM to model as they construct the exact building in real world, as new technologies and concepts such as the 'digital twin' [31] appear. The anticipated benefit of BIM is to be able to hold the material information, geographic and location data and even pursue energetic analysis [32]. Besides all these possibilities, the benefits of BIM are limited to the design and construction areas to be used by the technical agents, and not yet adapted to the postconstruction phase for occupant's appropriation. To take the benefit from the existing passive data of the building and to combine the passive data with the real-time ambient and environmental data as well as the personal data, a step further in design and development is needed. BIM is a good example of digitalization in architecture and a holistic digitaldesign thinking approach, which also leads the practitioner to take pseudo design innovation decisions. Moreover, regarding to the interdisciplinary approach and interoperability of BIM; Industry Foundation Class (IFC) is a term that is a standardized, digital description of the built asset industry. It is an open, international standard ISO 16739-1:2018, and promotes vendor-neutral, or agnostic, and usable capabilities across a wide range of hardware devices, software platforms, and interfaces for many different use cases [33]. One of the key aspects of BIM, which is interoperability, requires a fluid workflow between professions, offices. Even though BIM is a methodology to follow, each designer chooses to dominate one software, and specializes using that software as the main BIM tool. Working with files of different formats and the need to exchange information quickly and accurately, regarding to the burden of BIM. To face this type of problems on exchanging the information between software, the transfer of information which are both geometric and nongeometric; are carried out with the help of a common extension of IFC [34]. The Industry Foundation Classes is fundamental for BIM practice, and mostly when it comes to openBIM, which aims to allow the compatibility of flows. Using BIM provides transparent data flow, builds data collection and creates a system for sustain information gathering [35]. Moreover, in current day, the BIM research and development includes, but is not limited to, the sustainable practices, management and organizational issues around technology, and assisting technologies and methods [36].

On the other hand, sensor technologies, and the network by them; also known as: IoT provides interesting outcomes for built environment when integrated to current system. It is defined as the "interconnection of sensing and actuating devices providing the ability to share information across platforms through a unified framework, developing a common operating picture for enabling innovative applications" [37]. Implementing IoT technologies into AEC can improve the quality of human interaction experience within the built environment, allow real-time monitoring, enable smart built environment and reduce energy consumption. 
The interdisciplinary information sharing of BIM, which also could be defined as interoperability; when combined with IoT, has a great potential to be developed further. As a matter of fact, today there are over 40 billion connected devices worldwide. Moreover, there are thousands of new cities (and they are smarter ones), also new needs of those emergent territories and communities. The academy and industry must adapt to this emergence.

Furthermore, by this great emergence the data production reach to an extreme amount and the companies are collecting data more then they ever collected before. With all this data and all this processing power the industry now have incredibly smart computers and technologies which depend on the big data inputs. On the other hand, the digital revolution also affected the AEC industry, where almost all design and construction decisions are taken by digital means. Consequently, thanks to current technologies, the way that AEC industry consructs the built environment or how cities are planned and developed are changing accordingly.

In fact, being extremely smart is not enough anymore neither for devices, for buildings or cities. The built environment is evolving through being a living system or even an organism that constantly respond to the changes. The system requires smart citizens to operate them.

The role of BIM in understanding the future built environment intersects with the invisible cloud of existing and constantly produced information. Moreover, the real-time values would be crucial for planning new generation technologies for better futures. The big term of early 2000's; 'Sustainability' is not about preservation of energy or conservation of resources; it is also evolving through being a regenerative system. Efficient and reproductive planning for future built and natural environment are cohesive. For example, BIM could be a key feature to tackle to approach the global climate crisis, since it has all the information of a building, it can facilitate necessary information for current problems, to make us think and solve them. Those problems could be handled by data driven design solutions. Parallel to BIM logic, the aforementioned sensor technologies propose and interconnection of existing data and real-time information concerning energy efficiency or sustainability or even regenerative design. Blending BIM with IoT could make an impact on global climate change and give outstanding proposals for lowering the energy risk.

In current built environment, thanks to BIM, AEC industry is capable of analyze, monitor and document the information that is embedded into buildings. Yet, without integrating the user into this procedure, the system will always remain 'smart' and never be converted into 'responsive'. Human is the actuator of all of the functions and reasons, and we are the principal producer of all the aforementioned data in real-time. Smart systems make the user use the facilitated tools for specific goals. However, responsive systems enable the user to interact with the setting and be a part of the system. Therefore, the user both controls and manages the context. [38]. Sensor technologies are capable of capturing almost all kinds of data, but without the interaction of the smart user, the data would just perish and I don't see those types of smart systems could be considered as innovative anymore. We need data-driven design, which generates design-driven innovation. This requires engagement and interaction. This generates experience and a new type of 'innovation' [39-40]. This fact can be covered by a term; 'From Smart to Responsive'.

All the smart technologies are developed for the user, which is the occupant in the building or the citizen in the city. Which makes the user, the main generator of the life, and consequently, the data. Every action produce data and trigger another consequence, so that; all those actions and information should be issued for a purpose. This makes a building more than an object; it transforms an object that interacts and responds to conditions. Create symbiotic relations, or even act as an independent organism. The data of mobility, power, internet, energy delivery, water management, HVAC, sewage, recycling, food management, health-care, emergency and many more concerns could be embedded to those types of digital 
platforms, even with today's technology. Even well-being and happiness could be involved to the data information, by simply capturing their response.

On the other hand, Lean Construction is good example for the design-driven innovation. The term stands for a "way to design production systems to minimize waste of materials, time, and effort in order to generate the maximum possible amount of value" focusing on the whole life-cycle of the building. This approach tries to manage and improve construction processes with minimum cost and maximum value by considering customer needs [41]. Therefore, thanks to digital technologies and the regeneration of the cognition of the practitioner in academy, leads the future of built environment through the sustainable development.

\section{Discussion of MDEM upon design-driven innovation and production practices in AEC industry}

Companies within the AEC and architecture production related sectors tend to struggle when trying to adapt to new methodologies and technologies, as architecture has always been a slow paced and traditional field. Disruptive innovators and young professionals that can apply Multidimensional Exploration Methods in a regular basis have the power to bring new life into the field and push boundaries forward [42]. New digital fabrication technologies have brought together design, research and fabrication [43],closing the gap between what can and cannot be done in architecture offices and construction sites. New material developments also advance the knowledge further [44], where they can be thought and understood as proper digital materials, where matter can be encoded and located only where is needed.

Production softwares that uses BIM principles start to also close the gap between the designers' table and the industry; in example, Tekla [45]; offer the possibilities to embed data and user behavioral patterns into design and construction elements, in a deeper way than just adding information to the model and use as a visualization tool. Translating reality into parametric based modelling [46] is the preferred tool to be used by the sector. By all indicators, the future of design and production in AEC, incorporates data and parameters in the built environment, likewise, leading design and engineering companies started to adapt the required changes to their application and production methods.

Applied research projects in the material and automatization field can be a good example to illustrate how prototypes and proof of concepts from academic projects can be transferred and developed even further to suit architectural applications. 3D printing technologies for architecture using concrete and other cement-based materials, studied in a project by Dini on 2005 [47]; differ and add value in scale to first additive manufacturing concepts.

Moreover, the project results documented by the patent for the world's first 3D printer [48] prove that, the research with positive applied results within forty years' time-span. The development is shown by Apis Cor's research and development project [49] as; "The two-story government agency building in Dubai is reportedly the largest ever 3D printed" [50]. This generates new technological niches within the AEC sector. Usage of robotics in different stages of construction have proven positive to enhance human possibilities and what can be done with traditional materials when advanced technologies are used [51]. New systems and elements that have the possibility to selfassembly [52] prove that new ways of thinking, designing and even understanding the build environment are possible and efficient. New technologies such a VR-AR (Virtual Reality Augmented Reality) [53] demonstrate that human cognition and skill can be augmented by the use of technology, closing the gap between skilled on-site labor and digital BIM coordination models.

AEC companies need to adapt quickly to the new paradigm shift that is already happening in the academic sector, which inevitably will force the whole AEC industry to shift into innovative approaches to projects to stay competitive in their market niche. Moreover, the interdisciplinarity is an extremely important factor nowadays to develop 
and investigate outstanding results. As it is discussed above, AEC sector is triggered by various disciplines and so that, the practitioner must get used to combining knowledge from many other fields. MDEM allows the practitioner to develop the project with such a manner, because the method suggest questioning the unknown, therefore, the linear design-thinking with a single discipline, and a main concert that address a particular outcome. By the design phases and loops, the main goal is to accomplish one end-result. This end-result might be a very sophisticated and focused artifact, and it is highly appreciated. But on the other hand, with the interdisciplinary and empirical approach as there are several disciplines are blended in one project, the end results are also various. Each discipline that is included in the designed artifact contributes with the project by its' own particular content. Consequently, within the design thinking loops, each phase directs to another end-result, and outcomes direct the research to another. The outcomes trigger the innovation and more advanced research scope. Consequently, design-driven innovation procures.

Thanks to the MDEM, and its connection between the academy to industry, the gap from the knowledge to the practice would be closing up. Based on the spiral application method of MDEM, the learnt outcomes could be easily covered into practice. Moreover, when applied to the shift from the classroom to the professional field, by using the same method, the practitioner obtains satisfactory results by this holistic design-thinking approach.

By MDEM, the learner or the practitioner adopts a holistic design-thinking [54]. Designing by this holistic approach allows the designer to question and answer a wide range of essential concerns, as the design would be the output of the multidisciplinary modality. Using this approach that blends art, engineering, technology, science and sociology in proper means to the context, the result would be holistic, innovative and avantgarde. Relatively, the interdisciplinary approach between research fields should be considered for design-driven innovation. Actual design innovation is based on knowledge flows and the re-generated cognition of the new generation designers and engineers work in collaboration and gain inputs from several disciplines.

\section{Conclusion}

From academy to industry or from production practices back to research and development, there needs to exist a constant two-way connection. By this paper, we would like to create a link between academy to industry by Multidimensional Exploration Methodology, from learning environments to application and production practices, and vice-versa.

During their specific careers, the students should be trained by not only theoretical knowledge but also by a sustainable thinking and learning methodologies, which would guide them through design-driven innovation in later professional practice, much more connected to reality and matter. By this method, the learner digests the requirements of the actual built environment as well as the forthcoming necessities of global concerns, concepts that are needed in the current world. On the other hand, the designer, could apply this learning methods to generate knowledge within companies and industrial applications, professional fabrication, construction and production practices, and following the Design-Driven Innovation Compass techniques the projects would lead to outcomes in sustainable, innovative and efficient development.

Academic research and development are inseparable and they are both essential for the industry. Especially in current day where AEC based companies in hybrid technologies and investment on interdisciplinary approaches do not have time to focus on long term goals. The basis of innovation knowhow comes from the academy, even that the development, results and outcomes are specific to industry. In this paper, the focus is on the knowledge generated in academia and transferred and developed in professional practice, as is understood that Research \& Development tends to happen naturally in other industries apart from Architecture. 
Adapting the Multidimensional Exploration Method essentials to production practice directs the professionals to achieve design-driven innovation in their projects with unexpected but extraordinary results, since it is a journey to the unknown. The importance of interdisciplinary approaches by this research and development method is to achieve compatibility between knowledge fields and build bridges between them. Hybrid projects, learning from other disciplines and using co-creation as a design approach is highly encouraged in designdriven innovation as a process to increase interest, utility and complexity. Further vision of AEC industry has various enthusing prospectus. From theory to fabrication, construction and production, emergence of new technologies, software, devices and tools develop extremely fast. Digital-design thinking is essential for current practices, as well as design-driven innovation, in which staying connected and up-to-date is essential and crucial.

To conclude, MDEM in academy teaches by challenges, reshapes the cognition with added values and collective conscience, generates knowledge, enhances discovery and investigation. On the other hand, MDEM in industry leads the practitioner; (who is also a constant learner), to discover and develop solutions for existing problems.

This is how the industrial practice of new design and production practices in AEC industry (such as; $\mathrm{BIM}$, lean construction, sustainable practices new materials, emergent technologies such as 3D printing, self-assembly, interaction and big-data) might be engaged to each other and to be developed further. The whole process has digital-design thinking in current day which applied to MDEM as well.

The gains from academy are applied into industrial production, and it triggers the augmented results of the interdisciplinary projects, as well as creating more possibilities for adapting new generation technologies into practice. As a result, interconnection of innovation and development generates new knowledge, and creates knowledge flows between disciplines. This method provokes progressive results for AEC industry as proposing design-driven innovation examples, and creates many benefits for the industry and has positive outcomes for socio-economic and environmental aspects.

\section{Declaration of conflicting interests}

The author(s) declared no potential conflicts of interest with respect to the research, authorship, and/or publication of this article.

\section{References}

[1] Johansson-Sköldberg U, Woodilla J, Çetinkaya, M (2013) Design thinking: past, present and possible futures. Creativity and Innovation Management, 22(2): 121-146.

[2] Greenwald AG (1968) Cognitive Learning, Cognitive Response to Persuasion, And Attitude Change. Academic Press, New York, USA.

[3] Bloom B, Krathwohl D (1984) Taxonomy of Educational Objectives, Handbook 1: Cognitive Domain. (B. S. Addison, Ed.), Wesley Pub. Co., New York.

[4] Kolb D (1984) Experiential Learning: Experience as The Source of Learning and Development. Prentice-Hall, Englewood Cliffs, New Jersey, USA.

[5] Kolb D, Boyatzis R, Mainemelis C (1999) Experiential Learning Theory: Previous Research and New Directions. (R. J. Zhang, Ed.) Perspectives on Cognitive, Learning, and Thinking Styles, Routledge.

[6] Van Aken J (2005) Management research as a design science: articulating the research products of mode 2 knowledge production in management. British Journal of Management 16(1): 19-36.

[7] Henver A, March S, Park J, Ram S (2004) Design science in IS research. MIS Quarterly 28(1): 75105.

[8] Apple Inc. (2010). Challenge Based Learning A Classroom Guide. https://www.challengebasedlearning.org

[9] Nichols M, Cator K, Torres M (2016) Challenge Based Learner User Guide. Digital Promise, Redwood City.

[10] Sadler-Smith E (1996) Learning styles: a holistic approach. Journal of European Industrial Training, 20(7): 29-36. 
[11] Sadler-Smith E, Riding R (1999) Cognitive style and instructional preferences. Instructional Science 27: 355-371.

[12] Kolb A, Kolb D (2017) Learning styles and learning spaces: enhancing experiential learning in higher education. Academy of Management Learning \& Education 4(2): 193-212.

[13] Messick S (1976) Personality Consistencies in Cognition and Creativity. Individuality in Learning, San Francisco: Jossey-Bass.

[14] Pithers PT (2002) Cognitive learning style: a review of the field dependent-field independent approach. Journal of Vocational Education and Training 54(1): 117-132.

[15] Schön D (1984) The architectural studio as an exemplar of education for reflection-in-action. Journal of Architectural Education 38(1): 2-9.

[16] Ozkar, M. (2007). Learning by doing in the age of design computation. Computer-Aided Architectural Design Futures, Springer, Dordrecht.

[17] Tasl1-Pektas S (2010) Effects of cognitive styles on 2D drafting and design performance in digital media. International Journal of Technology and Design Education 20: 63-76.

[18] Dong A (2015) Design $\times$ Innovation: perspective or evidence-based practices. International Journal of Design, Creativity and Innovation 3: 148-163.

[19] Wrigley C, Mosely G, Tomitsch M (2018) Design thinking education: a comparison of massive open online courses. The Journal of Design, Economics, and Innovation 4(3): 275-292.

[20] Taheri M, Mayer L, von Schmieden K, Meinel C (2018) The DT MOOC Prototype: Towards Teaching Design Thinking at Scale. In M. C. Plattner H. (Ed.), Design Thinking Research: Understading Innovation, Springer.

[21] Roy R, Riedel J (1998) Design and innovation in successful product competition. Technovation 17(10): 537-594.

[22] Gerlitz L (2015) Design for Product and Service Innovation in Industry 4.0 and Emerging Smart Society. Journal of Security and Sustainability Issues 5(2): 181-198.

[23] Oxman R (2006) Theory and design in the first digital age. Design Studies 27(3): 229-265.

[24] Negroponte N (1995) Being Digital. Alfred A. Knopf, Inc., New York.

[25] Acklin C (2010) Design-driven innovation process model. Design Management Journal 5(1): 50-60.
[26] Verganti R (2009) Design Driven Innovation. Harvard Business Press, Boston.

[27] Schwab K (2017) The Fourth Industrial Revolution. (G. S. World Economic Forum, Ed.) Crown Business-Portfolio Penguin, United Kingdom.

[28] Fox M, Kemp M (2009) Interactive Architecture, Adaptive World. Princeton Architectural Press, New York.

[29] Kensek K (2014) Integration of Environmental Sensors with BIM: case studies using Arduino, Dynamo, and the Revit API. Informes de la Construcción 66(536): 31-39.

[30] Oxman R (2006) Re-thinking digital design. WIT Transactions on The Built Environment 90: 239247.

[31] Grieves M, Vickers J (2016) Digital Twin: mitigating unpredictable, undesirable emergent behavior in complex systems. In: Kahlen FJ., Flumerfelt S., Alves A. (eds) Transdisciplinary Perspectives on Complex Systems, Springer.

[32] Eastman C, Telicholz P, Sacks R, Liston K (2011) BIM Handbook: A Guide to Building Information Modeling for Owners, Managers, Designers, Engineers and Contractors. John Wiley \& Sons Inc, New Jersey.

[33] buildingSMART. (2019). Industry Foundation Classes (IFC). Recuperado el 21 de May de 2019, de buildingSMART International: https://www.buildingsmart.org/standards/bsistandards/industry-foundation-classes/

[34] e-Zigurat. (2019). IFC and BIM Interoperability. Retrieved May 21, 2019, from Zigurat: https://www.e-zigurat.com/blog/en/ifc-and-biminteroperability/

[35] United States National BIM Standard Project Comitee. (16 de October de 2016). Frequently Asked Questions About the National BIM Standard. Recuperado el 6 de November de 2019, de National BIM Standard: https://www.nationalbimstandard.org/faqs

[36] Becerik-Gerber B, Kensek K (2010) Building Information Modeling in architecture, engineering, and construction: emerging research directions and trends. Journal of Professional Issues in Engineering Education and Practice 3(3): 139-147.

[37] Gubbi J, Buyya R, Marusic S, Palaniswami M (2013) Internet of Things (IoT): a vision, architectural elements, and future directions. Future Generation Computer Systems 29(7): 1645-1660. 
[38] Birgonul Z (2021) A receptive-responsive tool for customizing occupant's thermal comfort and maximizing energy efficiency by blending bim data with real-time information: symbiotic data platform. Smart and Sustainable Built Environment, doi:10.1108/SASBE-11-2020-0175

[39] Birgonul Z, Cocho-Bermejo A, Sarrablo V (2018) Symbiotic Data Platform. Responsive Cities Symposium: Active Public Space 2017, Institute for Advanced Architecture of Catalonia, Barcelona.

[40] Birgonul Z, Yildiz E (2020) zeynepbirgonul/Symbiotic-Data-Platform/ Room Thermal Value Calculation via Revit/Dynamo/ Orchid Plug-in. Retrieved September 29, 2020, from GitHub: https://github.com/zeynepbirgonul/ Symbiotic-Data-Platform

[41] Koskela L, Howell G, Ballard G, Tommelein I (2002) The Foundations of Lean Construction. (Butterworth-Heinemann, Ed.) Butterworth Heinemann, Oxford, UK.

[42] Gausa M (2014) Celebrating Architecture Enjoying Research. IAAC Publishing, Barcelona.

[43] Gershenfeld N (2005) Fab: The Coming Revolution on Your Desktop--from Personal Computers to Personal Fabrication. Basic Books, New York, USA.

[44] Oxman N, Ortiz P, Gramazio F, Kohler M (2015) Material ecology. Computer-Aided Design 60: 1-2.

[45] Trimble Solutions Corporation. (2020). Trimble. Retrieved from Tekla: https://www.tekla.com

[46] Schumacher P (2008) Obtenido de Parametricisim as Style-Parametricist Manifesto: http://www.patrikschumacher.com/Texts/Parametr icism\%20as\%20Style.htm
[47] Sher D (2019) 3d Printing Media. Retrieved from One-to-one with Enrico Dini, the Italian who invented binder jetting for construction: https://www.3dprintingmedia.network/one-to-onewith-enrico-dini-the-italian-who-invented-binderjetting-for-constructions/

[48] Masters W (1979) Washington, DC: U.S. Patente n Patent and Trademark Office Patent No. 4,292,108.

[49] Apis Cor. (2020). Apis Cor: We Print Homes. Retrieved from 3D Printed Homes: https://www.apis-cor.com

[50] Zeiba D (2019) Apis Cor claims to have created the largest on-site 3D-printed building. Retrieved from The Architect's Newspaper: https://www. archpaper.com/2019/12/apis-cor-largest-on-site3d-printed-building-dubai/

[51] Gramazio F, Kohler M (2008) Digital Materiality in Architecture. Lars Müller Publishers, Zurich.

[52] Menges A, Tibbits S (2012) Design to SelfAssembly. Architectural Design, doi:10.1002/ad.1381

[53] Fologram (2018) Fologram. Retrieved from Fologram Pty Ltd. : https://fologram.com

[54] Birgonul Z (2020) Innovative Approaches for Avantgarde Artifacts: Discovering the Future, Reinventing the Design-Thinking. (In Eds. Garip E, Garip B) Methodologies for Design and Production Practices in Interior Architecture. IGI Global, Hershey, Pennsylvania, USA: 